\title{
Proton beam radiotherapy for patients with early-stage and advanced lung cancer: a narrative review with contemporary clinical recommendations
}

\author{
Jennifer S. Chiang^, Nathan Y. Yu^, Thomas B. Daniels, Wei Liu^, Steven E. Schild^, Terence T. Sio^ \\ Department of Radiation Oncology, Mayo Clinic, Phoenix, Arizona, USA \\ Contributions: (I) Conception and design: JS Chiang, NY Yu, W Liu, TT Sio; (II) Administrative support: None; (III) Provision of study materials \\ or patients: None; (IV) Collection and assembly of data: JS Chiang, NY Yu, W Liu, TT Sio; (V) Data analysis and interpretation: All authors; (VI) \\ Manuscript writing: All authors; (VII) Final approval of manuscript: All authors. \\ Correspondence to: Terence T. Sio, MD, MS. Associate Professor of Radiation Oncology, Mayo Clinic, Department of Radiation Oncology, 5777 East \\ Mayo Boulevard, Phoenix, Arizona 85054, USA. Email: Sio.Terence@mayo.edu.
}

\begin{abstract}
Although lung cancer rates are decreasing nationally, lung cancer remains the leading cause of cancer related death. Despite advancements in treatment and technology, overall survival (OS) for lung cancer remains poor. Proton beam therapy (PBT) is an advanced radiation therapy (RT) modality for treatment of lung cancer with the potential to achieve dose escalation to tumor while sparing critical structures due to higher target conformality. In early and late-stage non-small cell lung cancer (NSCLC), dosimetric studies demonstrated reduced doses to organs at risk (OARs) such as the lung, spinal cord, and heart, and clinical studies report limited toxicities with PBT, including hypofractionated regimens. In limited-stage SCLC, studies showed that regimens chemo RT including PBT were well tolerated, which may help optimize clinical outcomes. Improved toxicity profiles may be beneficial in post-operative radiotherapy, for which initial dosimetric and clinical data are encouraging. Sparing of OARs may also increase the proportion of patients able to complete reirradiation for recurrent disease. However, there are various challenges of using PBT including a higher financial burden on healthcare and limited data supporting its cost-effectiveness. Further studies are needed to identify subgroups that benefit from PBT based on prognostic factors, and to evaluate PBT combined with immunotherapy, in order to elucidate the benefit that PBT may offer future lung cancer patients.
\end{abstract}

Keywords: Proton beam therapy (PBT); non-small cell lung cancer (NSCLC); small cell lung cancer (SCLC)

Submitted Jul 23, 2020. Accepted for publication Nov 20, 2020.

doi: $10.21037 /$ jtd-20-2501

View this article at: http://dx.doi.org/10.21037/jtd-20-2501

\section{Introduction}

Although lung cancer rates are decreasing nationally (1), lung cancer remains the leading cause of cancer related death (2). In 2010, it was observed that $28 \%$ of patients had stage III disease at diagnosis, and this ratio had decreased slightly, as more patients were diagnosed with early (stages
I and II, 33\%) and stage IV (39\%) diseases (3). Despite advancements in treatment and technology, overall survival (OS) for lung cancer remains poor.

Approximately $85 \%$ of lung cancers diagnosed in the US are non-small cell lung cancer (NSCLC) (4). According to guidelines published by the American Society for Radiation

\footnotetext{
^ OCRID: Jennifer S. Chiang, 0000-0001-7461-4249; Nathan Y. Yu, 0000-0003-4059-650X; Wei Liu, 0000-0003-0935-3999; Steven E. Schild, 0000-0002-2850-4126; Terence T. Sio, 0000-0003-4210-5479.
} 
Oncology and National Comprehensive Cancer Network, stereotactic body radiation therapy (SBRT) is now regarded as the standard-of-care of medically inoperable, peripherally located early-stage NSCLC $(5,6)$. Due to lack of randomized data, SBRT is not recommended as an alternative to surgery in operable patients with standard operative risk at this time (5). Standard concurrent chemoradiation therapy (CRT) for LA-NSCLC (locally advanced NSCLC) has reached a therapeutic plateau, and variations in the chemotherapy backbone and addition of consolidation chemotherapy have failed to improve survival (7). Consolidation therapy with the anti-PD-L1 antibody, durvalumab, after CRT, improved progression-free survival (PFS) and OS in stage III NSCLC $(8,9)$. Early studies of dose escalation with photon-based RT suggested a role for dose escalation in improving locoregional control and OS, compared to historic data $(10,11)$. However, in the phase III RTOG 0617 trial, dose-escalated RT resulted in inferior OS compared to standard RT in patients with LA-NSCLC (12). The rate of grade $\geq 3$ esophagitis increased from $7 \%$ to $21 \%$, and increased severity of esophagitis was a negative predictor of OS. Several cardiac dose parameters, including heart V5, V30, and V40, were also negative predictors of OS, supporting a need to minimize radiation exposure to organs at risk (OAR) (13).

About $15 \%$ of all lung cancer diagnoses are small cell lung cancer (SCLC). SCLC is considerably more aggressive than NSCLC, often presenting with bulkier disease closer to dose-limiting mediastinal structures. The 5-year survival rate of SCLC is approximately $6 \%$, compared to $23 \%$ for NSCLC (4). Approximately twothirds of patients present with extensive stage SCLC, with the rest having thorax-confined, non-metastatic limitedstage SCLC (LS-SCLC). While median OS for LS-SCLC was previously approximately 1 year (14), it has improved due to advancements in image-based staging (15), treatment paradigms, and salvage therapies. The CONVERT trial, which accrued patients with LS-SCLC from 2008-2013, demonstrated a median OS of 25 months in the oncedaily RT group and 30 months in the twice-daily group after treatment with 3D conformal radiotherapy (3DCRT) or intensity-modulated radiation therapy (IMRT) with concurrent chemotherapy (16). A multi-institutional analysis demonstrated high rates of local control (LC) and low rates of treatment-related toxicities in the treatment of stage I SCLC with stereotactic ablative radiotherapy (SABR) (median dose 50 Gy) (17). LC was $97.4 \%$ and $96.1 \%$ at one and three years, respectively, and the median OS rate was
$71.1 \%$ and $34.6 \%$ at one and three years, respectively. A few studies of concurrent IMRT and chemotherapy for LSSCLC show promising outcomes and toxicities (18-20).

Proton beam therapy (PBT) has unique physical properties as manifested by the Bragg peak phenomena. As a charged particle moving through matter deposits energy and dose along its path, the energy loss per unit path length is relatively constant until it reaches a peak, beyond which very little residual dose remains (21). Thus, while photons cause ionizing damage to tissue throughout the entire axis of the beam, protons lack an exit dose. This decreases radiation exposure to OARs and potentially decreases radiation-induced toxicities (see Figure 1). This may particularly benefit lung cancer patients with poor pulmonary function, interstitial lung disease, cardiovascular disease, or patients receiving re-irradiation.

There are two predominant modes of proton delivery, passive scattering proton therapy (PSPT) and pencilbeam scanning (PBS) proton beam therapies. In PSPT, the tumor volume is irradiated as a whole, and conformal coverage in the distal edge of tumors is achieved using range modulation wheels, compensators, and beam apertures. In PBS, the tumor volume is treated spot-by-spot using a magnetic scanning system combined with energy modulation. PBS achieves higher target conformality in both the distal and proximal edge of tumors with delivery of intensity-modulated proton therapy (IMPT), reducing the low-to-intermediate dose to critical normal tissues relative to IMRT or PSPT in dosimetric studies (22). However, compared to PSPT, IMPT carries an increased risk of the interplay effect with tumor motion, which can degrade the quality and robustness of an IMPT plan (23). Four-dimensional computerized tomography, repainting techniques, and worst-case-scenario-based robust optimization are being utilized to improve the robustness of IMPT thoracic radiation delivery (24-30). Ultimately, PSPT plans would typically be less conformal, however, highly precise motional control requirements as afforded by PBS are not as much of a burden and challenge technically for thoracic tumors. The International Particle Therapy Co-operative Group (PTCOG) Thoracic Subcommittee released a consensus statement regarding this topic as well. This is of important consideration for centers who are actively evaluating vendors and their future capabilities and development regarding passive scatter versus pencil beam scanning techniques (31). We present the following article in accordance with the Narrative Review reporting checklist (available at http://dx.doi.org/10.21037/jtd-20-2501). 


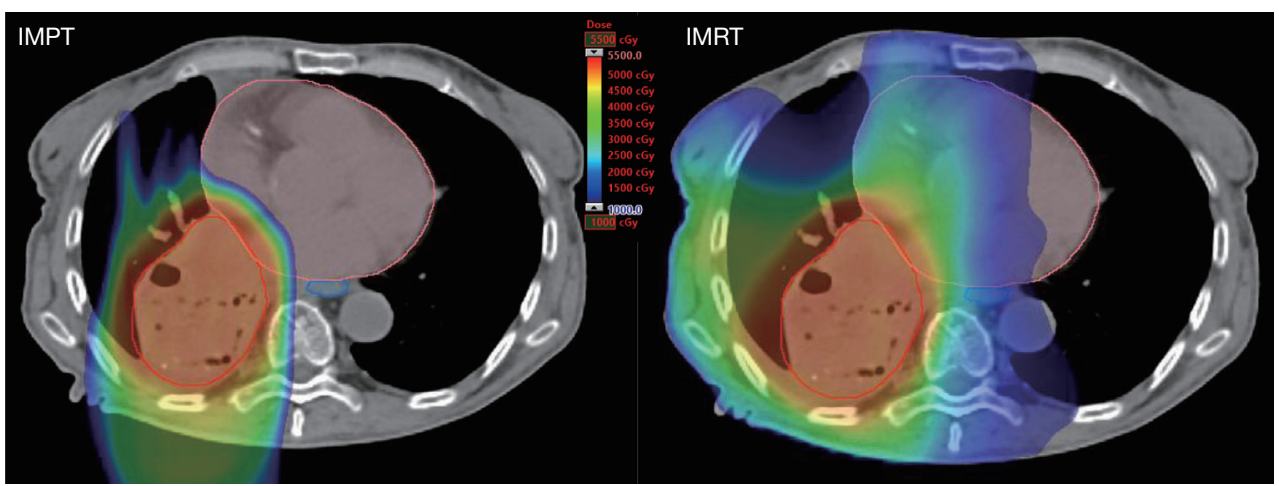

Figure 1 Axial comparison of an IMPT plan (left) vs. IMRT plan (right) of 50 Gy delivered in 20 daily fractions for a 71 -year-old female with locally-advanced NSCLC. A gross tumor volume (GTV) is defined in red. Esophagus is defined in blue. Heart is defined in pink. IMPT, intensity-modulated proton therapy; IMRT, intensity-modulated radiation therapy; NSCLC, non-small cell lung cancer.

\section{Rationale for PBT for lung cancer}

Due to the proximity of sensitive thoracic structures to conventional radiotherapy, such as the esophagus, heart, normal lungs, trachea and bronchi, and spinal cord, dose escalation in LA-NSCLC has had limited success (12). PBT may achieve dose escalation while providing superior OAR sparing. In one prospective trial, 5-year local recurrencefree survival rate was $85 \%$ for patients treated with $87.5 \mathrm{~Gy}$ in 2.5 Gy per fraction using PBT, with grade 3 dermatitis and pneumonitis in $2.9 \%$ and $2.9 \%$ of the patients only, respectively (32). Sejpal et al. demonstrated decreased rates of grade $\geq 3$ pneumonitis and esophagitis in patients with LA-NSCLC treated with chemotherapy and a median dose of 74 Gy of PBT, compared to those treated with chemotherapy and a median dose of 63 Gy of 3DCRT or IMRT (33). Toxicity rates were lower than those seen in RTOG 0617 and in studies with 3DCRT or IMRT and concurrent chemotherapy $(12,34,35)$. Therefore, PBT may allow for dose escalation while attaining long-term local control without increasing toxicities.

PBT may also improve safety profiles, due to its potential in improving the overall toxicity profile of CRT especially with high-grade side effects (36). Furthermore, many patients with lung cancer have significant comorbidities, more likely requiring treatment break or dose reduction, which are associated with poor outcomes in lung cancer therapies (37). Reduction of adverse outcomes with PBT may lead to increased ability to tolerate CRT, and subsequently may translate to better cancer outcomes as a result. This may be even more relevant for patients who require reirradiation due to locoregional recurrences but are still clinically fit for more curative therapeutic planning clinically.

While PBT does not have a clear role for treating smaller and peripheral lesions, it may be more advantageous in the treatment of larger or central tumors due to improved dose distributions to nearby OARs as the planning target volumes (PTV) become larger (38). One study demonstrated reduced dose to the chest wall and ribs in patients with larger peripheral tumors (39). PBT may also provide superior OAR sparing for central tumors, a location found to be a strong predictor of toxicity (40). This is likely secondary to reduced doses to the esophagus, heart, major vessels, and spinal cord. PBT has also demonstrated improved dosimetry in apical tumors (41), benefitting patients at risk of brachial plexopathy after SBRT (42).

\section{Indications for PBT for lung cancer}

\section{Small-cell lung cancer}

Current literature on PBT for LS-SCLC is limited to two studies. In a study of 6 patients treated with PBT and cisplatin/etoposide, 1-year PFS and OS were $66 \%$ and $83 \%$, respectively (43). Treatment was well tolerated with no patients experiencing grade $\geq 3$ acute or late events. Dosimetric analysis showed superior sparing of the lung and esophagus when compared to comparison IMRT plans.

In a larger study at the University of Pennsylvania, 30 patients were treated with cisplatin or carboplatin and etoposide concurrently with PBT (44). Patients received PBT twice daily with 45 Gy (1.5 Gy per fraction) or once daily with 59.4-66.6 Gy (1.8 Gy per fraction). Compared to IMRT, PBT plans demonstrated lower RT dose to the heart, lungs, and esophagus, with decreased lung volume 
receiving low dose bath. In patients treated with daily RT, there was one grade 3 pneumonitis and one grade 3 anorexia. In patients treated with twice daily RT, 1 patient experienced grade 3 pericardial effusion, and another experienced grade 4 esophagitis. LC rates were $85 \%$ and $69 \%$ at one and two years, respectively, and OS rates were $72 \%$ and $58 \%$, respectively. Five (17\%) patients experienced in-field recurrence, two of which were isolated in-field failures only.

Rwigema et al. demonstrated comparable survival figures to those of the CONVERT trial, and median OS and 2-year OS (28.2 months, $57.5 \%$ ) were greater than those of prior studies on photon-based CRT $(16,44)$. For example, the Intergroup 0096 study found 2-year OS rates of $41 \%$ (daily RT) and 47\% (twice-daily RT) and median OS of 19 months (daily RT) and 23 months (twice-daily RT) (36). In the Cancer and Leukemia Group B 39808 study, median OS was 22.4 months, and the 2-year OS rate was $48 \%$ (45). Importantly, all patients from the University of Pennsylvania study tolerated the regimen of CRT without RT breaks, and $93 \%$ of patients completed all four planned cycles of chemotherapy. PBT may improve tolerance of combined treatment modalities, optimizing clinical outcomes.

\section{Early-stage NSCLC}

Dosimetric studies of early-stage NSCLC demonstrated improved dose distribution with PBT compared to photonbased RT. In a study of patients with stage I NSCLC, PBT treatment plans demonstrated reduced lung V5, V10, and V20Gy when compared to SBRT treatment plans (38). In another study of patients with stage I and stage III NSCLC, comparison of dose-volume histograms similarly showed reduced mean total lung V5, V10, and V20Gy in PBT plans when compared 3DCRT plans, even with dose escalation (46). Furthermore, PBT reduced doses to the lung, spinal cord, heart, esophagus, and integral dose when compared with IMRT. A multicentric trial by the Radiation Oncology Collaborative Comparison (ROCOCO) compared photon, proton, and carbon-ion treatment plans for stage I NSCLC patients and reported lower mean dose and dose to $2 \%$ of CTV for proton and ion than IMRT. Doses to the spinal cord were lowest with double-scattered proton therapy plans (47).

Early PBT-based clinical studies found high rates of 2-year and 3-year OS, cause-specific survival (CSS), and PFS (Table 1) (48-50). Rates of toxicity were particularly low, with two studies showing no cases of grade $\geq 3$ lung and esophageal toxicities even with hypofractionation $(49,51)$. Two recent studies using proton and carbon ions demonstrated acceptable rates of toxicity with longer median follow-up times $(52,54)$. Two Japanese studies using different proton protocols demonstrated higher rates of rib fractures $(56,57)$.

In a 12-year randomized trial at Loma Linda University of 111 patients with early-stage NSCLC treated with hypofractionated PBT, increasing doses were associated with improved OS for the entire cohort (55). OS at four years was $18 \%, 32 \%$, and $51 \%$ for patients treated with 51 , 60 , and 70 Gy, respectively. For a subset of patients with peripheral T1 tumors treated with 60 or $70 \mathrm{~Gy}$, LC and OS at four years for were $96 \%$ and $60 \%$, respectively. For patients with T2 tumors, LC and OS were improved with dose escalation. Notably, no patients experienced clinically significant radiation pneumonitis or significant declines in pulmonary function one year after PBT.

A study at MD Anderson Cancer Center using a hypofractionated regimen of PBT (87.5 Gy/2.5 Gy fractions) also reported limited toxicities (59). At median follow-up time of 16.3 months, LC was $89 \%$, and distant metastasis-free survival (DMFS) was $72 \%$. Grade 3 dermatitis was observed in $17 \%$ of patients, and no grade 4 or 5 toxicities occurred. When the study was updated in 2017 and included 35 additional patients, OS rates were $86 \%, 43 \%$, and $28 \%$ at 1,3 , and 5 years, respectively (32). At a median follow-up time of 83.1 months, local recurrence-free and distant-metastasis-free survival rates were $85 \%$ and $54 \%$, respectively. There were 1 grade 3 dermatitis and 1 grade 3 pneumonitis.

Nantavithya $e t$ al. studied the efficacy and toxicity of stereotactic body proton therapy (SBPT) delivered through passive scattering technique compared to those of photon based SBRT (58). While the study closed early due to poor accrual, outcomes of 19 patients who received 50 Gy in 4 fractions were analyzed. At 3 years, rates for OS were 28\% and $90 \%$, LC $88 \%$ and $90 \%$, and regional control $48 \%$ and $90 \%$ in the SBRT and SBPT groups, respectively. In the SBPT group of patients, one case of grade 3 skin fibrosis was observed, but no grade 4 or 5 toxicities occurred.

Previous studies have reported correlations between clinical and PBT-related factors and patient outcomes. In the Loma Linda University study, stage IA patients had decreased tumor relapse rates $(13 \%)$ compared to stage IB patients (51\%) (55). Stage IA patients also experienced improved OS $(48,55)$. Shioyama et al. found that stage IA 


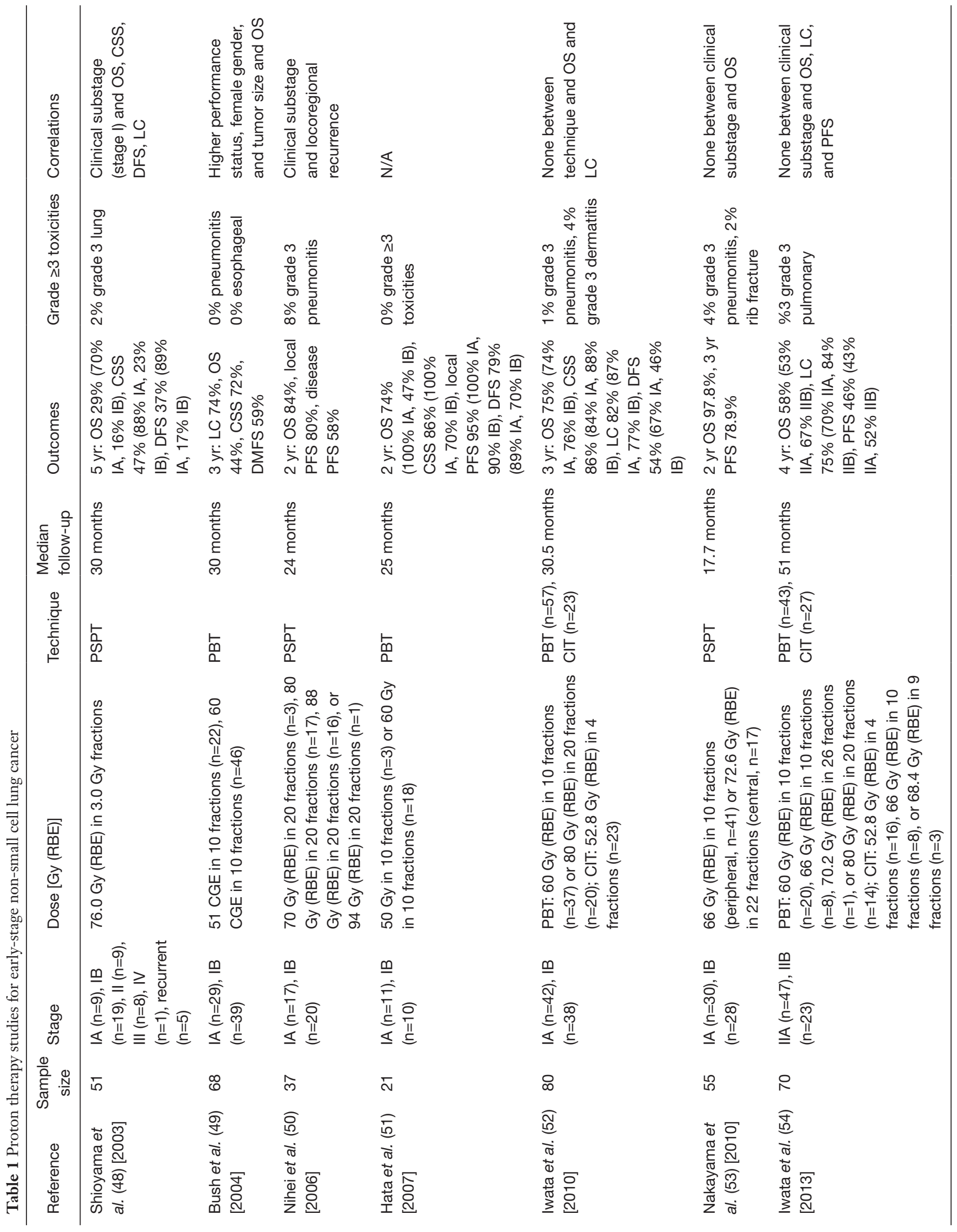




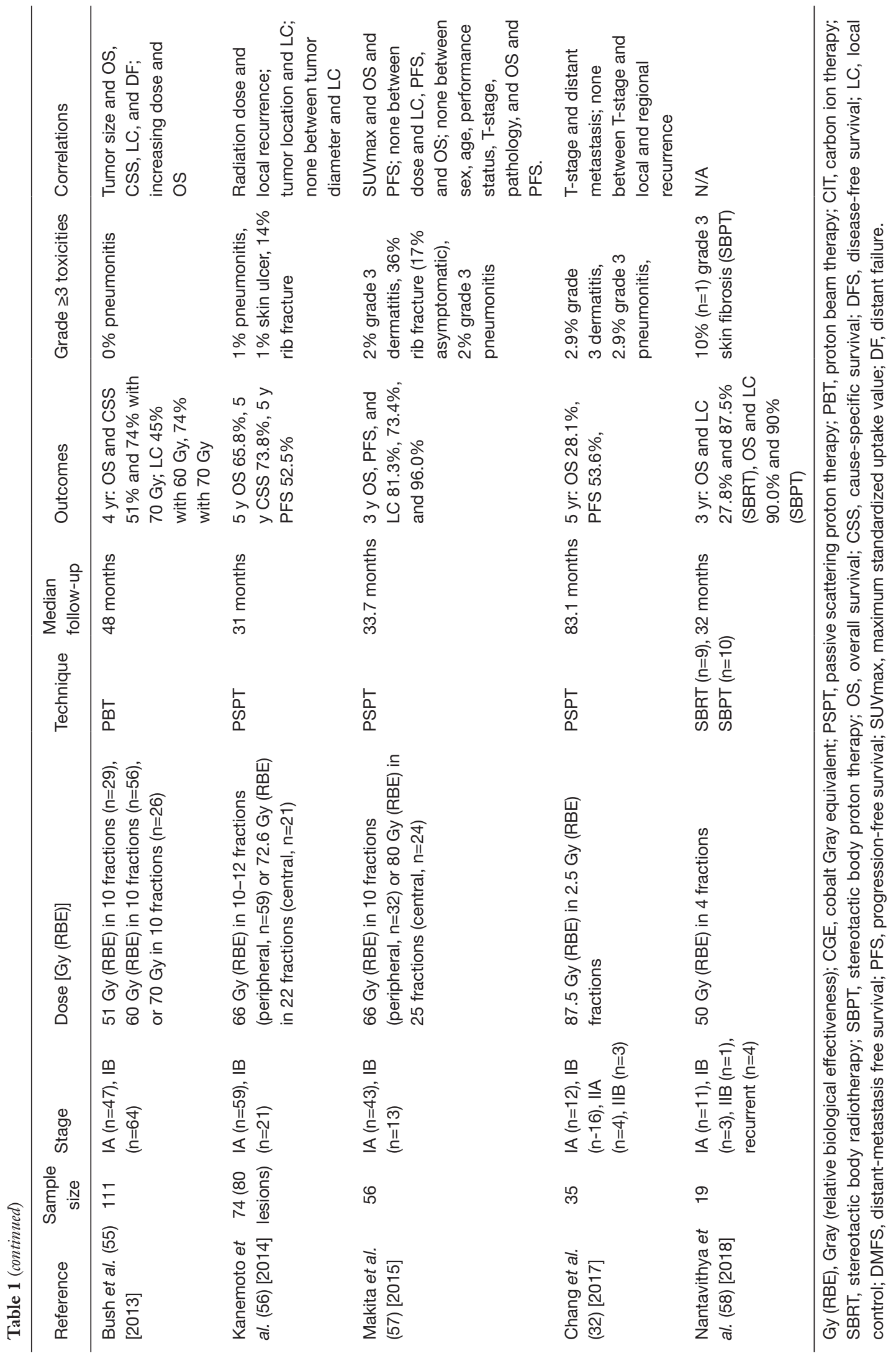


Table 2 Proton therapy studies for locally advanced non-small cell lung cancer

\begin{tabular}{|c|c|c|c|c|c|c|c|}
\hline Reference & $\begin{array}{l}\text { Sample } \\
\text { size }\end{array}$ & Stage & Radiation dose & Technique & $\begin{array}{l}\text { Median } \\
\text { follow-up }\end{array}$ & Outcomes & Grade $\geq 3$ toxicities \\
\hline $\begin{array}{l}\text { Sejpal et al. } \\
\text { (33) [2011] }\end{array}$ & 62 & III & $\begin{array}{l}74 \text { Gy }(\mathrm{RBE}) \\
\text { proton, } 63 \mathrm{~Gy} \\
\text { photon }\end{array}$ & $\begin{array}{l}\text { PBT, } \\
\text { 3DCRT, } \\
\text { IMRT }\end{array}$ & $\begin{array}{l}15.2 \\
\text { months }\end{array}$ & N/A & $\begin{array}{l}2 \% \text { and } 5 \% \text { grade } \geq 3 \text { pneumonitis } \\
\text { and esophagitis (proton), } 30 \% \text { and } \\
18 \% \text { pneumonitis and esophagitis } \\
\text { (3DCRT), } 9 \% \text { and } 44 \% \text { pneumonitis and } \\
\text { esophagitis (IMRT) }\end{array}$ \\
\hline $\begin{array}{l}\text { Nguyen et al. } \\
\text { (65) [2015] }\end{array}$ & 134 & $\begin{array}{l}\text { II }(n=21) \\
\text { III }(n=113)\end{array}$ & $\begin{array}{l}74 \text { Gy (RBE) or } \\
60-72 \text { Gy (RBE) } \\
\text { in } 2 \text { Gy (RBE) } \\
\text { fractions }\end{array}$ & PSPT & $\begin{array}{l}56.4 \\
\text { months }\end{array}$ & $\begin{array}{l}5 \text { yr: OS } 30 \%(I I), \\
25.3 \%(I I I A), 44.5 \% \\
\text { (IIIB); DFS } 19 \% \text { (II), } \\
17.4 \% \text { (IIIA), } 14.1 \% \\
\text { (IIIB) }\end{array}$ & $\begin{array}{l}4 \% \text { grade } 3 \text { esophagitis, } 2 \% \text { grade } 3 \\
\text { pneumonitis, } 6 \% \text { grade } 3 \text { dermatitis, } 1 \% \\
\text { grade } 4 \text { esophagitis }\end{array}$ \\
\hline $\begin{array}{l}\text { Liao et al. (63) } \\
\text { [2018] }\end{array}$ & 149 & IIB-IIIB & 74 Gy (RBE) & $\begin{array}{l}\text { PSPT } \\
(\mathrm{n}=92) \\
\text { IMRT } \\
(\mathrm{n}=57)\end{array}$ & $\begin{array}{l}24.1 \\
\text { months }\end{array}$ & $\begin{array}{l}1 \mathrm{yr}: \text { LF } 10.9 \% \\
\text { (IMRT), } 10.5 \% \\
\text { (PSPT) }\end{array}$ & $\begin{array}{l}7 \% \text { grade } \geq 3 \text { pneumonitis (IMRT), } 11 \% \\
\text { grade } \geq 3 \text { pneumonitis (PSPT) }\end{array}$ \\
\hline
\end{tabular}

Gy (RBE), Gray (relative biological effectiveness); PBT, proton beam therapy; PSPT, passive scattering proton therapy; 3DCRT, 3D conformal radiotherapy; IMRT, intensity-modulated radiation therapy; OS, overall survival; PFS, progression-free survival; DFS, diseasefree survival; LF, local failure

patients had longer cause-specific and disease-free survival ( $88 \%$ and $89 \%$ ) compared to stage IB patients $(23 \%$ and $17 \%$ ) (48). Similarly, in another study, locoregional recurrences occurred more frequently in stage IB patients $(30 \%)$ than in stage IA patients (6\%) (50). In contrast, other studies found no associations between clinical substage and OS $(32,52,53,57)$. While one study found radiation dose and tumor location to be significant prognostic factors for disease and local recurrence (56), another found no association between radiation dose and local control or PFS (57). Further studies are required to elucidate which clinical factors are associated with better outcomes for early-stage NSCLC patients.

\section{Locally advanced NSCLC}

Dosimetric and clinical studies suggest that PBT improved toxicity profiles compared to photon-based treatments. Compared to photon plans, proton plans for the treatment of LA-NSCLC have shown similarly robust clinical target volume (CTV) coverage and lower doses to OARs, including the heart, spinal cord, esophagus, and lung $(60,61)$. In a prospective longitudinal observational study of patient-reported outcomes, patients treated with PBT experienced decreased esophagitis-related pain as a local symptom compared to patients treated with 3DCRT or IMRT, even though the PBT group received a significantly higher prescription dose (62). In another study, PSPT has demonstrated decreased mean doses to V5-V10 Gy but increased doses to V20-V80 Gy volumes when compared to IMRT (63); the increased V20-V80 Gy likely reflects the 3D-conformal technique of PSPT with utility of large field margins. PSPT showed decreased mean doses to the heart at all measured dose levels.

Studies on patients with LA-NSCLC treated with PBT have also demonstrated excellent clinical outcomes with acceptable toxicities (Table 2). A Mayo Clinic study of 79 patients demonstrated similar OS, DMFS, and freedom from locoregional recurrence in patients treated with IMPT $v s$. IMRT at 1 year's mark (67). Five IMPT patients 
and 4 IMRT patients experienced grade 3 or 4 toxicities. One patient developed grade 5 pneumonitis in the setting of idiopathic pulmonary fibrosis 6 months after IMRT. In a study of 44 patients with stage III NSCLC treated with concurrent chemotherapy and PBT, median OS was 29.4 months, and 1-year OS and PFS rates were $86 \%$ and $63 \%$, respectively (64). At median follow-up time of 19.7 months, $21 \%$ of patients experienced local disease recurrence, with $9 \%$ being isolated local failure. The most common grade 3 toxicities were dermatitis and esophagitis, and no patients experienced grade 4 or 5 toxicities. The study was updated in 2017 to include 64 patients, with median follow-up of 27.3 months for all patients and 79.6 months for survivors (66). Median OS was 26.5 months, and 5-year OS and PFS rates were 29\% and $22 \%$, respectively. Rates of distant metastases and locoregional recurrence at 5 years were $54 \%$ and $28 \%$, respectively. Grade 3 acute esophagitis and late pneumonitis occurred in $8 \%$ and $12 \%$ of patients, respectively. Late grade 4 esophagitis and bronchial fistula occurred in 1 patient for each toxicity, and no acute or late grade 5 toxicities were observed.

Similar results were reported in another study of longterm clinical outcomes for 134 patients with stage II-III NSCLC treated with concurrent PBT and chemotherapy (65). Median follow-up time was 4.7 years, and median OS were 40.4 months and 30.4 months in patients with stage II and stage III NSCLC, respectively. Disease-free survival rates were $17 \%$ (stage II) and 18\% (stage III) at five years. Grade 3 pneumonitis, esophagitis, and dermatitis occurred in $1 \%$, $4 \%$, and $6 \%$ of patients, respectively, and one case of grade 4 esophagitis was observed.

A randomized trial comparing PSPT $v$ s. IMRT for locally advanced NSCLC did not demonstrate any difference in the primary endpoint of grade $\geq 3$ pneumonitis or local failure rates (63). It was noted that some of the initial patients on the PSPT arm that experienced pneumonitis could have been avoided with more modern planning techniques. In a National Cancer Data Base analysis of 243,822 patients with stage I-IV NSCLC (348 patients with PBT), 5-year OS was $23.1 \%$ and $13.5 \%$ for patients treated with PBT and photon-based RT, respectively (68). For patients with unresectable stage II and III NSCLC, PBT was also associated with better survival compared with photon-based RT. IMPT has not been compared directly with IMRT in this setting; further study of PBT vs. IMRT for locally advanced NSCLC is needed and we encourage continued enrollment on RTOG 1308, a randomized phase
III trial on stage II-IIIB NSCLC that is currently ongoing (ClinicalTrials.gov Identifier: NCT01993810, estimated completion date: Dec 31, 2025) (69).

Proton therapy may allow for safer dose escalation or delivery of hypofractionated radiation for LA-NSCLC. In a retrospective study of 62 patients with stage III NSCLC, PBT was delivered at a higher dose (74 Gy) than photonbased radiation (63 Gy) but resulted in lower rates of esophagitis and pneumonitis (33). Grade 3 or higher pneumonitis cases occurred in 2\%,30\%, and $9 \%$ of the PBT, 3DCRT, and IMRT groups, respectively. Rates of grade 3 or higher esophagitis cases were 5\%,18\%, and $44 \%$ in the PBT, 3DCRT, and IMRT groups, respectively. A multicenter phase 1 trial evaluating concurrent chemotherapy with increasing dose-per-fraction proton therapy for patients with unresectable stage II-III NSCLC found that hypofractionated proton therapy can be achieved with an acceptable rate of 1-year toxicities (70). Dose arms ranged from 2.5 Gy (RBE) per fraction to 4.0 Gy (RBE) per fraction to 60 or $60.01 \mathrm{~Gy}(\mathrm{RBE})$, and no maximum tolerated dose was identified. Two severe adverse events occurred among 7 patients treated at 3.53 Gy (RBE) per fraction [total 60.01 Gy (RBE)], both of which were attributed to chemotherapy. While the study closed early before accrual was met, these preliminary results are encouraging and support further study in a phase 2 trial.

\section{Post-operative radiotherapy (PORT) for NSCLC}

National Comprehensive Cancer Network guidelines recommend PORT for patients with $\mathrm{N} 2$ nodal involvement (especially for extracapsular extension) or with microscopic positive margin/residual disease. Because the primary concern regarding use of PORT is the possibility of toxicity negating the gain therapeutically, PBT becomes an attractive treatment option to minimize the risk to benefit ratio by OAR dose reduction.

Initial dosimetric and clinical data are encouraging. In a comparison of IMRT, PSPT, and IMPT plans for patients with resected stage IIA NSCLC treated with PORT, IMPT showed the greatest reduction in dose to OARs including the spinal cord, lung, and heart (71). In a study evaluating clinical outcomes of 61 patients who underwent PORT with PBT or IMRT, PBT was well tolerated with similar grade 3 pneumonitis (3.7\% proton vs. $2.9 \%$ IMRT) and lower grade 3 esophagitis (3.7\% proton, $11.8 \%$ IMRT) rates (72). One-year OS and local recurrence-free survival rates were also similar between the 2 cohorts. The Proton 
Table 3 Proton therapy studies for irradiation of recurrent non-small cell lung cancer

\begin{tabular}{|c|c|c|c|c|c|c|c|c|}
\hline Reference & $\begin{array}{l}\text { Sample } \\
\text { size }\end{array}$ & Technique & $\begin{array}{l}\text { Reirradiation } \\
\text { dose [Gy (RBE)] }\end{array}$ & $\begin{array}{l}\text { Median } \\
\text { time to } \\
\text { reirradiation }\end{array}$ & $\begin{array}{l}\text { Patients with } \\
\text { concurrent } \\
\text { chemotherapy }\end{array}$ & $\begin{array}{l}\text { Median } \\
\text { follow-up }\end{array}$ & Outcomes & Grade $\geq 3$ toxicities \\
\hline $\begin{array}{l}\text { McAvoy et al. } \\
\text { (76) [2014] }\end{array}$ & 102 & $\begin{array}{l}\text { PSPT, } \\
\text { IMRT }\end{array}$ & 60.48 EQD2 Gy & 36 months & $33 \%$ & $\begin{array}{l}6.5 \\
\text { months }\end{array}$ & $\begin{array}{l}2 \text { yr: OS 33\%, DMFS } \\
37 \%, \text { LFFS 34\% }\end{array}$ & $\begin{array}{l}7 \% \text { grade } \geq 3 \text { esophageal, } \\
10 \% \text { grade } \geq 3 \text { lung }\end{array}$ \\
\hline $\begin{array}{l}\text { Ho et al. (78) } \\
{[2018]}\end{array}$ & 27 & IMPT & 66 EQD2 Gy & 29.5 months & $48 \%$ & $\begin{array}{l}11.2 \\
\text { months }\end{array}$ & $\begin{array}{l}1 \mathrm{yr}: \text { OS } 54 \%, \text { LFFS } \\
78 \%, \text { PFS } 51 \%\end{array}$ & $7 \%$ late grade 3 lung \\
\hline $\begin{array}{l}\text { Badiyan et al. } \\
\text { (79) [2019] }\end{array}$ & 79 & PBT & 60-62.7 Gy & 19.9 months & $30 \%$ & $\begin{array}{l}10.7 \\
\text { months }\end{array}$ & $\begin{array}{l}1 \text { yr: OS } 60 \%, \text { PFS } \\
43 \%, \text { LFFS } 56.3 \%\end{array}$ & $\begin{array}{l}6 \% \text { and } 1 \% \text { acute and } \\
\text { late grade } 3 \text { toxicities }\end{array}$ \\
\hline
\end{tabular}

PSPT, passive scattering proton therapy; IMRT, intensity-modulated radiation therapy; IMPT, intensity-modulated proton therapy; PBT, proton beam therapy; Gy (RBE), Gray (relative biological effectiveness); EQD2, equivalent dose in 2-Gy fractions; OS, overall survival; PFS, progression-free survival; DMFS, disease-free survival; LFFS, local failure-free survival.

Collaborative Group is currently exploring the feasibility of a prospective study evaluating cardiopulmonary toxicity after proton $v s$. photon therapy, which may further elucidate the benefits that may be gained from PORT with PBT (73).

\section{Reirradiation for recurrent NSCLC}

Seventy percent of NSCLC patients receive radiation to the thorax as part of definitive or adjuvant treatment (74), but rates of locoregional relapse remain high (25-40\%). Many patients who experience recurrences after prior radiation are not considered candidates for surgery, and response to second-line chemotherapy is generally suboptimal (75). Concern regarding excess toxicity to OARs often precludes reirradiation (reRT) beyond palliative doses after definitive or postoperative RT. Thus, in the setting of reRT, continued dose reductions to OARs are of particular importance with newer RT innovations. Several studies of proton-based reRT demonstrate that a majority of patients are able to complete reRT, but subsequent toxicities vary in degree and incidence (Table 3).

In the largest series to date of PBT reRT, 79 patients received a median reRT dose of 60 Gy with or without concurrent chemotherapy (79). Median OS (measured from time of reirradiation completion), PFS, and local relapsefree survival were $15.2,10.5$, and 12.9 months, respectively. Acute and late grade 3 toxicities were observed in $6 \%$ and $1 \%$ of patients, respectively. Three deaths occurred which the authors attributed as possibly due to RT. Two patients died of pulmonary hemorrhage after receiving reRT for recurrences near or at the right hilum. Another patient died of cardiac arrest after receiving reRT concurrently with chemotherapy, for tumor recurrence near the aortic arch.

Investigators at MD Anderson Cancer Center evaluated the toxicity and efficacy of PBT for reRT in 33 patients using a median dose of 66 Gy (RBE) (74). Thirty-one patients (94\%) completed reRT, and median OS was 11.1 months. One-year OS, PFS, locoregional control, and DMFS were $47 \%, 28 \%, 54 \%$, and 39\%, respectively. Grade 3 or higher esophageal and pulmonary toxicities were observed in $9 \%$ and $21 \%$ of patients, respectively. No grade 5 toxicities were found.

Another study at MD Anderson Cancer Center evaluated outcomes of reRT (IMRT versus PSPT) with or without concurrent chemotherapy in 102 patients, $97 \%$ of whom completed treatment with a median reRT dose of $60.5 \mathrm{~Gy}$ (76). Median OS was 14.71 months, and 1-year OS was $53 \%$. Acute grade 3 or higher esophageal and pulmonary toxicities were $7 \%$ and $10 \%$, respectively, and concurrent chemotherapy was associated with higher risk of acute grade 2 or higher esophageal toxicities. Lung V10, V20, and mean lung doses were associated with higher risk of grade 2 or higher pulmonary toxicities. Tumor location, IMRT $v s$. PSPT, and equivalent dose in 2-Gy fractions (EQD2) were not associated with rates grade 2 or higher esophageal toxicities. No differences between LC, DMFS, or OS were found when comparing IMRT and PBT. For both RT modalities, time to reRT greater than 6 months predicted 
for better LC. Concurrent chemotherapy and higher EQD2 at reRT independently predicted for better OS.

A multi-institutional study evaluated 57 patients treated with PBT with or without concurrent chemotherapy, and $93 \%$ of patients completed treatment (77). At a median follow-up of 7.8 months, median OS was 14.9 months. Acute or late grade 3 or higher toxicities were observed in $42 \%$ of patients, including 6 cases of grade 5 toxicities. Increased toxicity in this experience may have been attributed to a higher rate of concurrent chemotherapy use (66\%), leading to significant chemotherapy-related grade 3 or higher toxicities such as neutropenia. Increased overlap with the central airway region was associated with increasing rates of grade 3 or higher toxicities, but decreased overlap was not associated with a clear OS benefit. Increased dose to both the esophagus and heart were also associated with higher rates of grade 3 or higher toxicities, and lower mean esophageal dose, but not heart dosage, translated to improved OS. In this study, concurrent chemotherapy did not predict for better OS.

In another study at MD Anderson Cancer Center, 27 patients were treated with a median dose of 66 Gy using IMPT with or without concurrent chemotherapy (78). Median OS was 18 months, and 1 -year OS was $54 \%$. The rates of freedom from local failure (LF), freedom from locoregional failure, and PFS at one year were 78\%, 61\% and $51 \%$, respectively. Improved PFS, freedom from LF, and freedom from locoregional failure were associated with a dose of 66 EQD2 or higher. Only 2 patients (7\%) experienced late grade 3 pulmonary toxicity, and no patients were found to have any grade 4 or 5 toxicities.

\section{Challenges of PBT ahead}

There are various challenges of using PBT and further study defining its role in the treatment of lung cancer patients especially prospectively is urgently required. The inherent heterogeneity of tissue densities of thoracic organs may impact dose distribution. The density of lung parenchyma is about one-third of that of solid tissues, and protons travel a greater physical distance in low-density tissues. Range uncertainty resulting from uncertainty in Hounsfield units of computed tomography images may also alter proton range and dose distribution. Additional motion uncertainty in the setting of thoracic tumors must be considered as well. Setup error and organ motion from respiration cause geometric displacement of tumors and normal tissues, blurring the dose gradient from target volume to normal tissue. Finally, anatomic changes during treatment may also add to PBT's uncertainty. The interplay effect particularly influences IMPT, as misplacement of individual pencil-beam spots relative to planned positions may result in underdosing the target volume or overdosing critical structures (80). Various treatment parameters may be modified to improve dose homogeneity in moving targets, such as using larger spot sizes, changing the spot delivery sequence, and employing re-scanning (80-82). Most new proton centers will be using scanning beam (i.e., IMPT) technologies, instead of PSPT. Working closely with our colleagues in medical physics will be paramount in optimizing this technology for lung cancer.

$\mathrm{PBT}$ is also significantly more expensive than conventional RT, considering the costs of building and operating particle accelerators. However, PBT may demonstrate improved cost-effectiveness ratios with safer hypofractionation, which has already been shown in photon therapy (83). In a meta-analysis comparing the cost-effectiveness of different modified fractionation and conventional fractionation schemes in photon therapy for unresected NSCLC patients, Ramaekers et al. demonstrated that modified fractionations yielded higher net monetary benefits, measured by multiplying the number of qualityadjusted life years with the ceiling ratio and subtracting the total costs (83). PBT may also prevent or delay treatment failure, decreasing additional costs from added hospitalizations and outpatient visits that would otherwise occur for patients treated with photon-based RT (84). Reduced toxicities including pneumonitis and esophagitis may also reduce costs associated with hospitalizations when comparing proton to photon therapy (31). Demonstrating cost effectiveness and delivering hypofractionated radiotherapy treatments will remain an important financial topic for consideration in adapting PBT for more clinics and hospitals in the United States and also globally (85).

From a systemic therapy's point of view, there has been a significant effort to harness the immune system to treat lung cancer. As a result, immune checkpoint inhibitors have changed the treatment paradigm for both SCLC and NSCLC. Following the results of IMpower133, the standard of care for de novo extensive-stage SCLC is chemotherapy followed by maintenance atezolizumab; median OS was 12.3 months, a 2-month benefit compared to patients treated without immunotherapy (86). In the CASPIAN trial, durvalumab plus platinum-etoposide improved OS in patients with extensive stage-SCLC compared to platinum-etoposide alone (87). Adjuvant 
durvalumab significantly prolonged OS for patients with unresectable, stage III NSCLC following definitive chemoradiation (9). As immunotherapy improves survival of patients with lung cancer, there is an urgent need to optimize novel RT techniques such as PBT to improve disease control and decrease long-term cardiopulmonary toxicity. Pneumonitis is a serious treatment-related toxicity from both immunotherapy and radiation. In the setting of immunotherapy, improving the therapeutic ratio with $\mathrm{PBT}$ has the potential to reduce toxicities such as radiation pneumonitis. Additionally, PBT deposits energy differently than traditional photon therapy leading to a higher relative radiobiologic effect (RBE) that has traditionally been presumed with a fixed ratio of 1.1. There is enthusiasm to investigate how radiation can promote an abscopal effect, a systemic anti-tumor response, in the context of immunotherapy. Future research is needed to study the radiobiologic impact of thoracic $\mathrm{PBT}$ on both tumoral and normal tissues, and also the interaction between $\mathrm{PBT}$ and immunotherapy.

Furthermore, additional studies demonstrating clinical benefit after PBT are necessary to justify the higher financial burden due to increased equipment and personnel cost. However, clinical access and accrual in PBT trials have proven to be difficult, because commercial payers have enacted prior authorization policies and other administrative barriers restricting the use and approval of PBT due to its higher cost and also a perceived lack of clinical benefits (88-90). A study at Rutgers Cancer Institute of New Jersey demonstrated that insurance coverage was not related to diagnosis, reRT, trial enrollment, or model policy guidelines of the American Society for Radiation Oncology (89). Over three years, prior authorization (PA) delayed treatment by an average of 3 weeks, and up to 4 months for those requiring appeal. A study at MD Anderson Proton Therapy Center in Houston, Texas similarly found no associations between insurance approval rates and trial enrollment or tumor type (90). Ironically, submission of a comparison treatment plan (PBT vs. photon) indicating dosimetric advantages were associated with decreased likelihood of approval. Ambiguity in the decision-making process for PBT approval by commercial payers and subsequent time delays to cancer treatment serve as a significant barrier to patient care (88-90). The logistics and delays of insurance approval were noted to be a factor in enrollment and randomization of a phase II study of SBPT $v s$. SABR for early-stage NSCLC, leading to early closure (58). In the future, use of guidelines from professional societies [such as ASTRO PBT Model Policy (91), approved June 2017], which are updated as more evidence becomes available, should increase the efficiency and transparency of the insurance approval process, promoting timely patient care and research (88).

\section{Conclusions}

PBT is a promising modality that delivers superior dose distributions and may improve local control without increasing side effects in lung cancer patients. As stage III NSCLC is a heterogeneous population with variable prognoses, we encourage future research to identify subgroups of patients that benefit from PBT based on prognostic factors, such as age, performance status, primary tumor location and size, single $v s$. multi-station $\mathrm{N} 2$ disease, individual patient anatomy, molecular factors, histopathology, re-irradiation, and cardiopulmonary comorbidities (92). As previous studies on clinical outcomes of reRT with PBT yielded variable outcomes, future studies may clarify what benefits may be gained in this subpopulation for which limiting toxicities to OARs is of primary concern. PBT may also be well suited for PORT, due to the majority of cases involving centrally located targets that are less susceptible to motion uncertainties than are peripheral lesions (73). Future studies may evaluate possible reductions in cardiac damage with PBT, which is especially valuable in patients with pre-existing comorbidities. The role of PBT needs to be defined and optimized in the context of immunotherapy for lung cancer. Enthusiastic enrollment of patients in clinical trials will help establish evidence-based clinical indications and technology guidelines to clarify the benefit that PBT may offer for patients with lung cancer.

\section{Acknowledgments}

Funding: None.

\section{Footnote}

Reporting Checklist: The authors have completed the Narrative Review reporting checklist. Available at http:// dx.doi.org/10.21037/jtd-20-2501

Conflicts of Interest: All authors have completed the ICMJE uniform disclosure form (available at http://dx.doi. org/10.21037/jtd-20-2501). TTS reports that he provides 
strategic and scientific recommendations as a member of the Advisory Board and speaker for Novocure, Inc., which is not in any way associated with the content or disease site as presented in this manuscript. SES reports that he writes and edits for UpToDate on various subjects related to radiation oncology. The other authors have no conflicts of interest to declare.

Ethical Statement: The authors are accountable for all aspects of the work in ensuring that questions related to the accuracy or integrity of any part of the work are appropriately investigated and resolved.

Open Access Statement: This is an Open Access article distributed in accordance with the Creative Commons Attribution-NonCommercial-NoDerivs 4.0 International License (CC BY-NC-ND 4.0), which permits the noncommercial replication and distribution of the article with the strict proviso that no changes or edits are made and the original work is properly cited (including links to both the formal publication through the relevant DOI and the license). See: https://creativecommons.org/licenses/by-nc-nd/4.0/.

\section{References}

1. American Cancer Society. Facts \& Figures 2020. 2020.

2. Siegel RL, Miller KD, Jemal A. Cancer statistics, 2018. CA Cancer J Clin 2018;68:7-30.

3. Morgensztern D, Ng SH, Gao F, et al. Trends in stage distribution for patients with non-small cell lung cancer: a National Cancer Database survey. J Thorac Oncol 2010;5:29-33.

4. American Society of Clinical Oncology. Non-small cell lung cancer: Statistics. 2019.

5. Videtic GMM, Donington J, Giuliani M, et al. Stereotactic body radiation therapy for early-stage non-small cell lung cancer: Executive Summary of an ASTRO Evidence-Based Guideline. Pract Radiat Oncol 2017;7:295-301.

6. Ettinger DS, Wood DE, Akerley W, et al. NCCN Guidelines Insights: Non-Small Cell Lung Cancer, Version 4.2016. J Natl Compr Canc Netw 2016;14:255-64.

7. Senan S, Brade A, Wang L-h, et al. PROCLAIM: Randomized Phase III Trial of Pemetrexed-Cisplatin or Etoposide-Cisplatin Plus Thoracic Radiation Therapy Followed by Consolidation Chemotherapy in Locally Advanced Nonsquamous Non-Small-Cell Lung Cancer. J Clin Oncol 2016;34:953-62.

8. Antonia SJ, Villegas A, Daniel D, et al. Durvalumab after
Chemoradiotherapy in Stage III Non-Small-Cell Lung Cancer. N Engl J Med 2017;377:1919-29.

9. Antonia SJ, Villegas A, Daniel D, et al. Overall Survival with Durvalumab after Chemoradiotherapy in Stage III NSCLC. N Engl J Med 2018;379:2342-50.

10. Bradley JD, Bae K, Graham MV, et al. Primary analysis of the phase II component of a phase I/II dose intensification study using three-dimensional conformal radiation therapy and concurrent chemotherapy for patients with inoperable non-small-cell lung cancer: RTOG 0117. J Clin Oncol 2010;28:2475-80.

11. Socinski MA, Blackstock AW, Bogart JA, et al. Randomized phase II trial of induction chemotherapy followed by concurrent chemotherapy and dose-escalated thoracic conformal radiotherapy (74 Gy) in stage III non-small-cell lung cancer: CALGB 30105. J Clin Oncol 2008;26:2457-63.

12. Bradley JD, Hu C, Komaki RU, et al. Long-Term Results of RTOG 0617: A Randomized Phase 3 Comparison of Standard Dose Versus High Dose Conformal Chemoradiation Therapy +/- Cetuximab for Stage III NSCLC. Int J Radiat Oncol Biol Phys 2017;99:S105.

13. Chun SG, Hu C, Choy H, et al. Impact of IntensityModulated Radiation Therapy Technique for Locally Advanced Non-Small-Cell Lung Cancer: A Secondary Analysis of the NRG Oncology RTOG 0617 Randomized Clinical Trial. J Clin Oncol 2017;35:56-62.

14. Pignon JP, Arriagada R, Ihde DC, et al. A Meta-Analysis of Thoracic Radiotherapy for Small-Cell Lung Cancer. N Engl J Med 1992;327:1618-24.

15. Xanthopoulos EP, Corradetti MN, Mitra N, et al. Impact of PET staging in limited-stage small-cell lung cancer. J Thorac Oncol 2013;8:899-905.

16. Faivre-Finn C, Snee M, Ashcroft L, et al. Concurrent once-daily versus twice-daily chemoradiotherapy in patients with limited-stage small-cell lung cancer (CONVERT): an open-label, phase 3, randomised, superiority trial. Lancet Oncol 2017;18:1116-25.

17. Verma V, Simone CB 2nd, Allen PK, et al. MultiInstitutional Experience of Stereotactic Ablative Radiation Therapy for Stage I Small Cell Lung Cancer. Int J Radiat Oncol Biol Phys 2017;97:362-71.

18. Shirvani SM, Juloori A, Allen PK, et al. Comparison of 2 common radiation therapy techniques for definitive treatment of small cell lung cancer. Int J Radiat Oncol Biol Phys 2013;87:139-47.

19. Xia B, Hong LZ, Cai XW, et al. Phase 2 study of accelerated hypofractionated thoracic radiation therapy and concurrent chemotherapy in patients with limited- 
stage small-cell lung cancer. Int J Radiat Oncol Biol Phys 2015;91:517-23.

20. Liu Z, Liu W, Ji K, et al. Simultaneous integrated dose reduction intensity-modulated radiotherapy applied to an elective nodal area of limited-stage small-cell lung cancer. Exp Ther Med 2015;10:2083-7.

21. Schild SE, Rule WG, Ashman JB, et al. Proton beam therapy for locally advanced lung cancer: A review. World J Clin Oncol 2014;5:568-75.

22. Zhang X, Li Y, Pan X, et al. Intensity-modulated proton therapy reduces the dose to normal tissue compared with intensity-modulated radiation therapy or passive scattering proton therapy and enables individualized radical radiotherapy for extensive stage IIIB non-small-cell lung cancer: a virtual clinical study. Int J Radiat Oncol Biol Phys 2010;77:357-66.

23. Kraus KM, Heath E, Oelfke U. Dosimetric consequences of tumour motion due to respiration for a scanned proton beam. Phys Med Biol 2011;56:6563-81.

24. Liu C, Sio TT, Deng W, et al. Small-spot intensitymodulated proton therapy and volumetric-modulated arc therapies for patients with locally advanced non-small-cell lung cancer: A dosimetric comparative study. J Appl Clin Med Phys 2018;19:140-8.

25. Liu C, Schild SE, Chang JY, et al. Impact of Spot Size and Spacing on the Quality of Robustly Optimized Intensity Modulated Proton Therapy Plans for Lung Cancer. Int J Radiat Oncol Biol Phys 2018;101:479-89.

26. Liu W, Li Y, Li X, et al. Influence of robust optimization in intensity-modulated proton therapy with different dose delivery techniques. Med Phys 2012;39:3089-101.

27. Liu W, Liao Z, Schild SE, et al. Impact of respiratory motion on worst-case scenario optimized intensity modulated proton therapy for lung cancers. Pract Radiat Oncol 2015;5:e77-86.

28. Liu W, Schild SE, Chang JY, et al. Exploratory Study of 4D versus 3D Robust Optimization in Intensity Modulated Proton Therapy for Lung Cancer. Int J Radiat Oncol Biol Phys 2016;95:523-33.

29. Liu W, Zhang X, Li Y, et al. Robust optimization in intensity-modulated proton therapy. Med Phys 2012;39:1079-91.

30. Liu C, Yu NY, Shan J, et al. Technical Note: Treatment planning system (TPS) approximations matter - comparing intensity-modulated proton therapy (IMPT) plan quality and robustness between a commercial and an in-house developed TPS for nonsmall cell lung cancer (NSCLC). Med Phys 2019;46:4755-62.
31. Chang JY, Jabbour SK, De Ruysscher D, et al. Consensus Statement on Proton Therapy in Early-Stage and Locally Advanced Non-Small Cell Lung Cancer. Int J Radiat Oncol Biol Phys 2016;95:505-16.

32. Chang JY, Zhang W, Komaki R, et al. Long-term outcome of phase I/II prospective study of dose-escalated proton therapy for early-stage non-small cell lung cancer. Radiother Oncol 2017;122:274-80.

33. Sejpal S, Komaki R, Tsao A, et al. Early findings on toxicity of proton beam therapy with concurrent chemotherapy for non-small cell lung cancer. Cancer 2011;117:3004-13.

34. Yom SS, Liao Z, Liu HH, et al. Initial evaluation of treatment-related pneumonitis in advanced-stage nonsmall-cell lung cancer patients treated with concurrent chemotherapy and intensity-modulated radiotherapy. Int J Radiat Oncol Biol Phys 2007;68:94-102.

35. Jiang ZQ, Yang K, Komaki R, et al. Long-term clinical outcome of intensity-modulated radiotherapy for inoperable non-small cell lung cancer: the MD Anderson experience. Int J Radiat Oncol Biol Phys 2012;83:332-9.

36. Turrisi AT, Kim K, Blum R, et al. Twice-Daily Compared with Once-Daily Thoracic Radiotherapy in Limited SmallCell Lung Cancer Treated Concurrently with Cisplatin and Etoposide. N Engl J Med 1999;340:265-71.

37. Karim SM, Zekri J. Chemotherapy for small cell lung cancer: a comprehensive review. Oncol Rev 2012;6:e4.

38. Kadoya N, Obata Y, Kato T, et al. Dose-volume comparison of proton radiotherapy and stereotactic body radiotherapy for non-small-cell lung cancer. Int J Radiat Oncol Biol Phys 2011;79:1225-31.

39. Welsh J, Amini A, Ciura K, et al. Evaluating proton stereotactic body radiotherapy to reduce chest wall dose in the treatment of lung cancer. Med Dosim 2013;38:442-7.

40. Timmerman R, McGarry R, Yiannoutsos C, et al. Excessive toxicity when treating central tumors in a phase II study of stereotactic body radiation therapy for medically inoperable early-stage lung cancer. J Clin Oncol 2006;24:4833-9.

41. Register SP, Zhang X, Mohan R, et al. Proton stereotactic body radiation therapy for clinically challenging cases of centrally and superiorly located stage I non-small-cell lung cancer. Int J Radiat Oncol Biol Phys 2011;80:1015-22.

42. Chang JY, Balter PA, Dong L, et al. Stereotactic Body Radiation Therapy in Centrally and Superiorly Located Stage I or Isolated Recurrent Non-Small-Cell Lung Cancer. Int J Radiat Oncol Biol Phys 2008;72:967-71.

43. Colaco RJ, Huh S, Nichols RC, et al. Dosimetric rationale and early experience at UFPTI of thoracic proton therapy 
and chemotherapy in limited-stage small cell lung cancer. Acta Oncol 2013;52:506-13.

44. Rwigema JM, Verma V, Lin L, et al. Prospective study of proton-beam radiation therapy for limited-stage small cell lung cancer. Cancer 2017;123:4244-51.

45. Bogart JA, Herndon JE 2nd, Lyss AP, et al. 70 Gy thoracic radiotherapy is feasible concurrent with chemotherapy for limited-stage small-cell lung cancer: analysis of Cancer and Leukemia Group B study 39808. Int J Radiat Oncol Biol Phys 2004;59:460-8.

46. Chang JY, Zhang X, Wang X, et al. Significant reduction of normal tissue dose by proton radiotherapy compared with three-dimensional conformal or intensity-modulated radiation therapy in Stage I or Stage III non-small-cell lung cancer. Int J Radiat Oncol Biol Phys 2006;65:1087-96.

47. Wink KCJ, Roelofs E, Simone CB 2nd, et al. Photons, protons or carbon ions for stage I non-small cell lung cancer - Results of the multicentric ROCOCO in silico study. Radiother Oncol 2018;128:139-46.

48. Shioyama Y, Tokuuye K, Okumura T, et al. Clinical evaluation of proton radiotherapy for non-small-cell lung cancer. Int J Radiat Oncol Biol Phys 2003;56:7-13.

49. Bush DA, Slater JD, Shin BB, et al. Hypofractionated proton beam radiotherapy for stage I lung cancer. Chest 2004;126:1198-203.

50. Nihei K, Ogino T, Ishikura S, et al. High-dose proton beam therapy for Stage I non-small-cell lung cancer. Int J Radiat Oncol Biol Phys 2006;65:107-11.

51. Hata M, Tokuuye K, Kagei K, et al. Hypofractionated high-dose proton beam therapy for stage I non-smallcell lung cancer: preliminary results of a phase I/II clinical study. Int J Radiat Oncol Biol Phys 2007;68:786-93.

52. Iwata H, Murakami M, Demizu Y, et al. High-dose proton therapy and carbon-ion therapy for stage I nonsmall cell lung cancer. Cancer 2010;116:2476-85.

53. Nakayama H, Sugahara S, Tokita M, et al. Proton beam therapy for patients with medically inoperable stage I nonsmall-cell lung cancer at the university of tsukuba. Int J Radiat Oncol Biol Phys 2010;78:467-71.

54. Iwata H, Demizu Y, Fujii O, et al. Long-term outcome of proton therapy and carbon-ion therapy for large (T2aT2bN0M0) non-small-cell lung cancer. J Thorac Oncol 2013;8:726-35.

55. Bush DA, Cheek G, Zaheer S, et al. High-dose hypofractionated proton beam radiation therapy is safe and effective for central and peripheral early-stage non-small cell lung cancer: results of a 12-year experience at Loma Linda University Medical Center. Int J Radiat Oncol Biol
Phys 2013;86:964-8.

56. Kanemoto A, Okumura T, Ishikawa H, et al. Outcomes and prognostic factors for recurrence after high-dose proton beam therapy for centrally and peripherally located stage I non-small-cell lung cancer. Clin Lung Cancer 2014;15:e7-12.

57. Makita C, Nakamura T, Takada A, et al. High-dose proton beam therapy for stage I non-small cell lung cancer: Clinical outcomes and prognostic factors. Acta Oncol 2015;54:307-14.

58. Nantavithya C, Gomez DR, Wei X, et al. Phase 2 Study of Stereotactic Body Radiation Therapy and Stereotactic Body Proton Therapy for High-Risk, Medically Inoperable, Early-Stage Non-Small Cell Lung Cancer. Int J Radiat Oncol Biol Phys 2018;101:558-63.

59. Chang JY, Komaki R, Wen HY, et al. Toxicity and patterns of failure of adaptive/ablative proton therapy for earlystage, medically inoperable non-small cell lung cancer. Int J Radiat Oncol Biol Phys 2011;80:1350-7.

60. Li X, Kabolizadeh P, Yan D, et al. Improve dosimetric outcome in stage III non-small-cell lung cancer treatment using spot-scanning proton arc (SPArc) therapy. Radiat Oncol 2018;13:35.

61. Nichols RC, Huh SH, Hoppe BS, et al. Protons safely allow coverage of high-risk nodes for patients with regionally advanced non-small-cell lung cancer. Technol Cancer Res Treat 2011;10:317-22.

62. Wang XS, Shi Q, Williams LA, et al. Prospective Study of Patient-Reported Symptom Burden in Patients With NonSmall-Cell Lung Cancer Undergoing Proton or Photon Chemoradiation Therapy. J Pain Symptom Manage 2016;51:832-8.

63. Liao Z, Lee JJ, Komaki R, et al. Bayesian Adaptive Randomization Trial of Passive Scattering Proton Therapy and Intensity-Modulated Photon Radiotherapy for Locally Advanced Non-Small-Cell Lung Cancer. J Clin Oncol 2018;36:1813-22.

64. Chang JY, Komaki R, Lu C, et al. Phase 2 study of highdose proton therapy with concurrent chemotherapy for unresectable stage III nonsmall cell lung cancer. Cancer 2011;117:4707-13.

65. Nguyen QN, Ly NB, Komaki R, et al. Long-term outcomes after proton therapy, with concurrent chemotherapy, for stage II-III inoperable non-small cell lung cancer. Radiother Oncol 2015;115:367-72.

66. Chang JY, Verma V, Li M, et al. Proton Beam Radiotherapy and Concurrent Chemotherapy for Unresectable Stage III Non-Small Cell Lung Cancer: Final 
Results of a Phase 2 Study. JAMA Oncol 2017;3:e172032.

67. Yu NY, DeWees TA, Liu C, et al. Early Outcomes of Patients With Locally Advanced Non-small Cell Lung Cancer Treated With Intensity-Modulated Proton Therapy Versus Intensity-Modulated Radiation Therapy: The Mayo Clinic Experience. Adv Radiat Oncol 2019;5:450-8.

68. Higgins KA, O'Connell K, Liu Y, et al. National Cancer Database Analysis of Proton Versus Photon Radiation Therapy in Non-Small Cell Lung Cancer. Int J Radiat Oncol Biol Phys 2017;97:128-37.

69. Radiation Therapy Oncology Group. Comparing Photon Therapy To Proton Therapy To Treat Patients With Lung Cancer. Available online: https://ClinicalTrials.gov/show/ NCT01993810. 2018.

70. Hoppe BS, Nichols RC, Flampouri S, et al. Hypofractionated Proton Therapy with Concurrent Chemotherapy for Locally Advanced Non-Small Cell Lung Cancer: A Phase 1 Trial from the University of Florida and Proton Collaborative Group. Int J Radiat Oncol Biol Phys 2020;107:455-61.

71. Berman AT, Teo BK, Dolney D, et al. An in-silico comparison of proton beam and IMRT for postoperative radiotherapy in completely resected stage IIIA non-small cell lung cancer. Radiat Oncol 2013;8:144.

72. Remick JS, Schonewolf C, Gabriel P, et al. First Clinical Report of Proton Beam Therapy for Postoperative Radiotherapy for Non-Small-Cell Lung Cancer. Clin Lung Cancer 2017;18:364-71.

73. Shepherd AF. Proton therapy for post-operative radiation therapy of non-small cell lung cancer. Transl Lung Cancer Res 2018;7:205-9.

74. McAvoy SA, Ciura KT, Rineer JM, et al. Feasibility of proton beam therapy for reirradiation of locoregionally recurrent non-small cell lung cancer. Radiother Oncol 2013;109:38-44.

75. Noble J, Ellis PM, Mackay JA, et al. Second-line or Subsequent Systemic Therapy for Recurrent or Progressive Non-Small Cell Lung Cancer: A Systematic Review and Practice Guideline. J Thorac Oncol 2006;1:1042-58.

76. McAvoy S, Ciura K, Wei C, et al. Definitive reirradiation for locoregionally recurrent non-small cell lung cancer with proton beam therapy or intensity modulated radiation therapy: predictors of high-grade toxicity and survival outcomes. Int J Radiat Oncol Biol Phys 2014;90:819-27.

77. Chao HH, Berman AT, Simone CB 2nd, et al. MultiInstitutional Prospective Study of Reirradiation with Proton Beam Radiotherapy for Locoregionally
Recurrent Non-Small Cell Lung Cancer. J Thorac Oncol 2017;12:281-92.

78. Ho JC, Nguyen QN, Li H, et al. Reirradiation of thoracic cancers with intensity modulated proton therapy. Pract Radiat Oncol 2018;8:58-65.

79. Badiyan SN, Rutenberg MS, Hoppe BS, et al. Clinical Outcomes of Patients With Recurrent Lung Cancer Reirradiated With Proton Therapy on the Proton Collaborative Group and University of Florida Proton Therapy Institute Prospective Registry Studies. Pract Radiat Oncol 2019;9:280-8.

80. Grassberger C, Dowdell S, Lomax A, et al. Motion interplay as a function of patient parameters and spot size in spot scanning proton therapy for lung cancer. Int J Radiat Oncol Biol Phys 2013;86:380-6.

81. Li H, Zhu XR, Zhang X. Reducing Dose Uncertainty for Spot-Scanning Proton Beam Therapy of Moving Tumors by Optimizing the Spot Delivery Sequence. Int J Radiat Oncol Biol Phys 2015;93:547-56.

82. Zeng C, Plastaras JP, Tochner ZA, et al. Proton pencil beam scanning for mediastinal lymphoma: the impact of interplay between target motion and beam scanning. Phys Med Biol 2015;60:3013-29.

83. Ramaekers BLT, Joore MA, Lueza B, et al. Cost Effectiveness of Modified Fractionation Radiotherapy versus Conventional Radiotherapy for Unresected NonSmall-Cell Lung Cancer Patients. J Thorac Oncol 2013;8:1295-307.

84. Kutikova L, Bowman L, Chang S, et al. The economic burden of lung cancer and the associated costs of treatment failure in the United States. Lung Cancer 2005;50:143-54.

85. Hunter D, Mauldon E, Anderson N. Cost-containment in hypofractionated radiation therapy: a literature review. J Med Radiat Sci 2018;65:148-57.

86. Horn L, Mansfield AS, Szcz sna A, et al. First-Line Atezolizumab plus Chemotherapy in Extensive-Stage Small-Cell Lung Cancer. N Engl J Med 2018;379:2220-9.

87. Paz-Ares L, Dvorkin M, Chen Y, et al. Durvalumab plus platinum-etoposide versus platinum-etoposide in firstline treatment of extensive-stage small-cell lung cancer (CASPIAN): a randomised, controlled, open-label, phase 3 trial. Lancet 2019;394:1929-39.

88. Yu NY, Sio TT, Mohindra P, et al. The Insurance Approval Process for Proton Beam Therapy Must Change: Prior Authorization Is Crippling Access to Appropriate Health Care. Int J Radiat Oncol Biol Phys 2019;104:737-9.

89. Gupta A, Khan AJ, Goyal S, et al. Insurance Approval for Proton Beam Therapy and its Impact on Delays in 
Treatment. Int J Radiat Oncol Biol Phys 2019;104:714-23. 90. Ning MS, Gomez DR, Shah AK, et al. The Insurance Approval Process for Proton Radiation Therapy: A Significant Barrier to Patient Care. Int J Radiat Oncol Biol Phys 2019;104:724-33.

Cite this article as: Chiang JS, Yu NY, Daniels TB, Liu W, Schild SE, Sio TT. Proton beam radiotherapy for patients with early-stage and advanced lung cancer: a narrative review with contemporary clinical recommendations. J Thorac Dis 2021;13(2):1270-1285. doi: 10.21037/jtd-20-2501
91. American Society for Radiation Oncology. ASTRO Model Policies: Proton Beam Therapy 2017.

92. Verma V, Chang JY. Dose-escalation of locally advanced non-small cell lung cancer with proton beam therapy. Transl Lung Cancer Res 2018;7:S280-2. 